\title{
O PAPEL MEDIADOR DA SUPERVISÃO NO PROCESSO ENSINO APRENDIZAGEM JUNTO AOS PROFESSORES EM RELAÇÃO À ALFABETIZAÇÃO DA EJA.
}

Regina Maria da Silva Porto ${ }^{1}$

RESUMO: O artigo vem discutir sobre a importância do professor supervisor ao mediar seu trabalho junto aos professores da EJA, que uma modalidade de ensino onde trabalha com jovens e adultos que não tiveram oportunidade de estarem em uma sala de aula no tempo correto, mas que trazem consigo experiências de vida que acompanhada ao ensino aprendizagem, poderá levar esses alfabetizando a criticidade, tornando-os cidadãos capazes de modificarem sua rotina de vida para melhor, sendo que os profissionais que trabalha com essa modalidade deve se preocupar em se instruir constantemente associando teoria e prática. O texto nos mostra o quão se faz importante trabalhar em parceria dentro do âmbito escolar sem usar de arbitrariedade, para que esses alunos da EJA não se sintam diminuídos e se afastem da escola, o processo de aprender com suas experiências têm que partir de algum estímulo prazeroso. Sendo assim o trabalho vem com o intuito de demonstrar o processo ensino aprendizagem de alfabetização com alunos da EJA, na mediação da equipe pedagógica junto aos professores.

Palavras-chave: Modalidade de Ensino-EJA; Ensino e Aprendizagem; Supervisão.

ABSTRACT: The article discusses the importance of the supervising teacher in mediating his work with the teachers of the EJA, that a teaching modality where he works with young people and adults who had no opportunity to be in a classroom at the right time, but that bring with them life experiences that, accompanied by teaching and learning, may lead them to literacy and criticality, making them citizens able to modify their life routine for the better, and professionals working with this modality should worry about instructing themselves constantly associating theory. and practice. The text shows us how important it is to work in partnership within the school without arbitrariness, so that these students of EJA do not feel diminished and away from school, the process of learning from their experiences must start from some stimulus. pleasurable. Thus, the work aims to demonstrate the teaching-learning process of literacy with EJA students, in the mediation of the pedagogical team with the teachers.

Keywords: Teaching Mode-EJA; Teaching and learning; Supervision.

1 Mestranda em ciências Sociais pela Faculdade Interamericana de Ciências Sociais. Asunción-PY. 


\section{INTRODUÇÃO}

A proposta desse artigo é refletir sobre como o supervisor articula-se em busca de proposta para mediar junto aos seus discentes em favor da alfabetização para oportunizar os jovens e adultos que não tiveram acesso as escolas por vários motivos no tempo regular, e demonstrar que esses indivíduos têm o direito de elevar sua escolaridade por meio de novos conhecimentos que podem ser utilizadas nas diferentes relações cotidianas.

Apresenta também a importância da reconstrução do saber docente de professores da educação de jovens e adultos, mostrando a necessidade de se especializar principalmente, porque essa modalidade de ensino é pouco estudada na formação inicial de professores, e esse docente tem que alem de conhecer o currículo, deve saber da realidade desses estudantes, como inferir para que cada um se desenvolva efetivamente suas habilidades. Como afirma Freire, 2002, "quem forma se forma e reforma ao formar e quem é formado forma-se e forma ao ser formado."

Entretanto sabe que a EJA é uma modalidade de ensino defendida pelo artigo 37 da LDB (lei n`9.394/96) que nasceu da clara necessidade de oferecer uma melhor chance para pessoas que por qualquer razão não concluíram o ensino fundamental e/ ou médio na idade própria.

\section{O PROCESSO HISTÓRICO DA SUPERVISÃO DO EJA}

O mundo vive em constante transformação em todo instante se descobre algo novo que associado com a experiência do antigo pode se tornar uma arma quase perfeita, desde que associada a muito estudo e pesquisa, assim também se enquadra o ambiente escolar.

Antes de começar a discutir como pode ser a contribuição do supervisor no processo ensino aprendizagem dos alunos da EJA, é importante buscar entender como era visto esse profissional no surgimento desta carreira. 
No passado a proposta da supervisão relacionava-se a vistoria do espaço escolar por parte dos nobres e sacerdotes, a comunidade escolar não se identificava com os supervisores, por terem esse o papel meramente fiscalizador. Etimologicamente segundo Ferreira, 2001, "supervisão é a ação ou efeito de supervisiona, vigiar".

Segundo Ribeiro (2001, p.19):

A educação básica de adultos começou a delimitar seu lugar na história da educação no Brasil a partir da década de 30, quando finalmente começa a se consolidar um sistema público de educação elementar no País. Neste período, a sociedade brasileira passava por grandes transformações, associadas ao processo de industrialização e concentração populacional em centros urbanos. A oferta de ensino básico gratuito estendia-se consideravelmente, acolhendo setores sociais cada vez mais diversos.

Quando o supervisor busca guiar-se na ética profissional e fugir da função meramente fiscalizadora, o mesmo respeita sempre seu semelhante, conhecendo e trabalhando de forma ativa para que o ambiente escolar tenha harmonia e o objetivo da ação educativa seja efetivo.

A relação do supervisor com o ambiente escolar deve ser de trocas, oportunidades de aprender e ensinar constantemente junto aos seus docentes, esse profissional tem que ter bom índice de instrução e integração.

O bom relacionamento e o amor pela profissão de supervisor levam a comunidade escolar a vibrar dentro de um espaço diferenciado indo sempre em busca de conhecer outros mundos de possibilidades educacionais, levando-os de forma responsável e inovadora ao processo ensino aprendizagem. Dentro do ambiente escolar deve-se levar a sério a relação supervisor-professor com gravidade e profundidade, e isso só se fazem possível quando ambos confiam uns nos outros e em suas capacidades de aprender, de explorar e compreender.

O supervisor do século $X X I$ deve direcionar sua visão globalmente e atingir todos os setores de uma comunidade escolar, fugindo sempre de que seu papel seja somente em levar folhinhas de atividades prontas, para que seu professor possa estagnar no conhecer e aprender junto com seus discentes. $O$ 
coordenador pedagógico deve desenvolver em si e em seus professores sentimentos, habilidades, atitudes que são base na atuação relacional: ouvir, falar, olhar, prezar.

"O coordenador pedagógico precisa conhecer e valorizar a trama das relações interpessoais nas quais ele, coordenador, e seus professores interagem. E, ao lidar com professores que trabalham com seres humanos usando a si próprios como instrumentos de trabalho, precisa desenvolver com esses professores uma relação calorosa autêntica, relação que Ihes permita desenvolverem-se como pessoas que vão se relacionar com pessoas".( ALMEIDA E PLACCO, 2002, p.70)

A formação continuada do professor supervisor ajuda com ações formadoras no grupo de professores. O supervisor só consegue essas mudanças no espaço escolar quando eles buscam se especializar e quando sabem realmente suas atribuições e as direciona de forma eficiente para que haja realmente mudanças junto ao seu grupo, não deixando ser envolvidos com responsabilidades que não Ihes cabe, por medo ou preguiça de buscar exercer suas tarefas.

Então, se percebe o quão se mudou a ideia de supervisão de outrora, que seguia uma linha, onde professores eram vigiados a todo instante para ser pego em erro, o nosso presente nos mostra uma ação parceira e participativa no processo ensino aprendizagem, em busca do diferencial através de constantes estudos, pois sabemos que a educação está em constante mudança e as verdades sempre são questionadas, em busca de novas verdades, fazendo um paralelo com FREIRE (1996), quando ele cita que, "ensinar exige consciência do inacabamento", assim somos com nossas ações educativas, sempre em busca do novo, do melhor a ser utilizado no espaço a que me encontro, sempre em prol do conhecimento e da inquietação intelectual.

O supervisor tem que se permitir olhar para sua prática e buscar descobrir novas possibilidades, não imaginadas anteriormente. 


\section{1 - ENSINO E APRENDIZAGEM COM ALUNO DA EJA}

Etimologicamente, Ferreira, 2001 afirma que, ensinar significa ministrar 0 conhecimento, transmitir, instruir adestrar. Aprendizagem, tomar conhecimento de, ato ou efeito de aprender, quando associadas essas duas palavras, poderíamos compreendê-la como ato de transmitir algum conhecimento, mas se nos apegarmos a esse conceito não poderíamos trabalhar com nossos alunos o refletir, o raciocinar, o reconstruir experiências.

$\mathrm{Na}$ EJA esse processo de ensino aprendizagem deve ser significativo, fogem da educação tradicional onde professores e livros didáticos são os possuidores do saber e que o processo de ensino e aprendizagem se faz por transmissão e memorização acumulativas de conteúdo.

Nessa modalidade de ensino o alfabetizador deve planejar em cima do conhecimento prévio dos alfabetizando para que os conteúdos possam ser ensinados e aprendidos adequadamente, e esse processo só se torna eficaz quando esse professor preocupa-se em conhecer a realidade cultural de seus alunos da EJA.

O educador que reconhece em seu aluno um ser pensante consegue atingir o real significado das palavras, ensinar e aprender, pois esse se coloca como aliado desse aprendiz. Como afirma Lopes e Souza s.d.p.15, "o educador não deve ser arrogante, pois o aluno pode se sentir inferiorizado discriminado". E esse aluno da EJA tem muito a contribuir no processo ensino aprendizagem, quando percebem que estão sendo tratados como agentes ativos, se sentem mais interessados e mais responsáveis.

A EJA necessita de professores preparados para trabalhar de forma diferenciada que não venha preencher ou indenizar a escolaridade perdida do aluno e que não os trate como crianças e sim como indivíduos que tem direitos a permanência nas escolas e continuação de seus estudos.

A educação de jovens e adultos não pode ser considerada um fardo que os alfabetizando devem carregar, mas sim um estímulo para que suas vidas melhorem. E o papel do professor se torna fundamental na transformação dessa realidade. $O$ educador ultrapassa o reunir grupos de pessoas em um 
determinado espaço, ele se preocupa com o ensinar e o aprender, busca compreender melhor seu aluno e sua realidade diária.

Diante do que foi discutido o docente deve procurar associar os saberes acadêmicos com sua prática tendo responsabilidades e compromisso com suas escolhas, sob uma ação pautada pela ética e pelo compromisso profissional quanto pessoal.

\section{2 - MODALIDADE DE ENSINO EJA}

Classificação dada pela Lei de Diretrizes e Bases da Educação Nacional (LDB), de 1996, a determinadas formas de educação que podem localizar-se nos diferentes níveis da educação escolar (educação básica e educação superior). São modalidades de ensino, segundo a LDB: Educação de Jovens e Adultos, a Educação Profissional e a Educação Especial. Dessa forma, por exemplo, a educação de jovens e adultos pode ser ofertada como ensino fundamental ou médio.

A EJA é oferecida a pessoas que não tiveram acesso aos estudos na idade correta no ensino fundamental e médio e esse têm que ser oferecido de forma gratuita, considerando as características do aluno, seus interesses, condições de vida e de trabalho, mediante cursos e exames.

A Educação de Jovens e Adultos, como modalidade de ensino não pode ser pensada como uma oferta de educação menos importante, mas buscar meios para concebê-la de forma a envolver sua clientela trabalhando suas especificidades, não admitindo que professore a apresente como uma versão reduzida e simplificada do currículo de ensino, buscando sempre seguir os princípios orientadores de contextualização e flexibilidade, fundamentais para a sua estruturação. A legislação é clara, recomenda-se utilizar alternativas adequadas à realidade do sujeito da EJA, sendo que a prática alfabetizadora deve levar em conta os saberes, os conhecimentos então obtidos e as experiências de vida dos alfabetizando. 
Conhecer a história de vida e sua cultura desses jovens e adultos que não tiveram acesso a escola no ensino regular devido a diversos fatores tais quais de ordem econômica, social, política, geográfica e cultural é de fundamental importância, pois grande parte deste público sente vergonha de estarem na escola, por acreditar que o ambiente escolar é um espaço de aprendizagem para criança.

Alfabetizadores da EJA não devem esquecer que esses alunos, trazem do seu cotidiano, saberes que podem ser aproveitados visto que a escola não é o único espaço de produção e socialização de conhecimento e esse professor tem como objetivo estabelecer uma reflexão crítica, ampliando o horizonte desses alfabetizando. Como afirmava Freire, (1996, p.33) "Ensinar exige respeito aos saberes dos educandos".

Ao tentar compreender alfabetização de jovens e adultos, deve-se entender primeiro, esse sujeito como um ser ativo, que interpreta, entende e infere no mundo que vive.

O papel do supervisor e do professor, que venha a trabalhar na EJA não deve se limitar a cumprir o que os outros lhe ditam, mas deve apresentar uma postura de agente ativo, um profissional que reflete sua própria prática, que constrói conhecimentos e constrói a si próprio. Tanto o alfabetizador quanto o alfabetizando precisam se perceber enquanto sujeitos históricos e sociais da dinâmica educacional.

"Constituir-se alfabetizador de jovens e adultos é mais do que constituirse meramente um professor que dá aulas, pois o compromisso com os oprimidos torna-o um agente com a possibilidade de instigar processo de conscientização que primam pela libertação em detrimento do aprisionamento junto aos seus alfabetizando nas mesmas correntes da justiça social. Trata-se de um posicionar-se que requer, acima de tudo, uma identidade conscientizada”. (SOEK, HARACEMIV E STOLTZ, 2009,p.24)

E é buscando essa transformação consciente como alfabetizador, que o sujeito consegue romper com os ideais dominantes, e não é simplesmente com a obtenção de um diploma que o alfabetizador se forma alfabetizado, mediante sua formação o mesmo deve proporcionar muito mais que saber sistematizado, 
mais respeitar a valorização da cultura das necessidades do individuo num processo de liberdade do pensar, compreendendo que alfabetizador e alfabetizando se desenvolve juntos.

O desafio na alfabetização da EJA, além da forma de ensinar, é como entrelaçar esse ensino a realidade desses jovens e adultos. A diretriz curricular nacional para a EJA enfatiza que enquanto modalidade de educação básica deve considerar o perfil dos alfabetizando ao utilizar um modelo pedagógico. Essas mesmas diretrizes motivam que a EJA exerça a função reparadora, equalizadora e qualificadora no processo educacional.

Reparadora, no sentido de que todo indivíduo tem que ter acesso a um bem real, social, sendo imprescindível um modelo educacional que crie condições pedagógicas aceitável para as necessidades de aprendizagem especificas de alfabetizando jovens e adultos.

Equalizador, oportunizando igualmente jovens e adultos na inclusão ao mundo do trabalho, e a EJA tem um papel fundamental por que leva esta clientela a atualizarem suas habilidades, seus conhecimentos, trocas de experiências e de terem acesso a novas culturas e novas formas de trabalho.

Qualificadora, porque busca uma educação constante, mostrando que o individuo é incompleto, por isso que nessa modalidade os trabalhos pedagógicos são voltados a valorizar os interesses individuais e o ritmo de aprendizagem do educando.

A EJA nesse contexto busca formar cidadãos capazes de ter autonomia intelectual, que possam inferir na sociedade, lutando por seus direitos acoplando os seus conhecimentos ensinados pela escola, para se aperfeiçoar no mundo do trabalho e na sociedade em si, associando experiências cotidianas com atividades produtivas, para o enfrentamento a possíveis conflitos que se apresente na sociedade atual. 


\section{2- A EDUCAÇÃO NA CONSTRUÇÃO DA CIDADANIA ATRAVÉS DO EJA.}

O mundo contemporâneo impõe imensos desafios os seus habitantes: a velocidade em que circula a informação, o complexo jogo político entre as nações, a dinâmica que rearranja as fronteiras entre os países, o crescimento das cidades e a qualidade de vida urbana, as transformações na vida no campo e as questões ambientais, entre tantas outras.

Desde muito cedo, os jovens estão expostos a essas transformações e passam por rico processo de percepção do espaço ao seu redor, expressão do meio social em vivem. Esta Biologia da vida cotidiana afeta até mesmo as crianças e adolescentes que infelizmente não freqüentam a escola. Por meio de suas brincadeiras, em seu movimento corporal, em seus desenhos, em sua capacidade de observação, nas pequenas dramatizações e jogos teatrais, elas entendem e se apropriam do espaço geográfico.

A Declaração de Hamburgo (1997, p.19 e 20) preconiza, a este respeito que:
A educação de adultos inclui a educação formal, a educação não formal e o espectro da aprendizagem informal e incidental disponível numa sociedade multicultural, onde os estudos baseados na teoria e na prática devem ser reconhecidos. [...] Engloba todo o processo de aprendizagem formal ou informal, onde as pessoas [...] desenvolvem suas habilidades, enriquecem seu conhecimento e aperfeiçoam suas qualificações técnicas e profissionais, direcionando-as para a satisfação de suas necessidades e as de sua sociedade.

Assim, a perspectiva é de uma aprendizagem permanente, de uma formação continuada, considerando como elemento central dessa formação a construção da cidadania em função dos processos sociais que se modificam.

Para Paulo freire, (1996: P. 25) coloca que "ensinar não é transmitir conhecimentos, mas criar as possibilidades para a sua produção".

Nesse sentido, o caráter social da vida dos seres humanos é um processo uma construção, da qual participa cada indivíduo na relação com os outros. As relações entre as pessoas são mediadas pelas instituições em que elas convivem pelas classes e categorias as que pertencem e pelos interesses 
e poderes que nelas circulam. E por essa razão que, mais do que se falar numa natureza humana, como um universal abstrato, vale referir-se a condição humana, forma concreta da existência dos seres humanos na cultura e na história. A cidadania é também uma condição construída historicamente.

Em relação aos ideais que devem ser perseguidos, nesta modalidade de ensino, a Declaração de Hamburgo (1997, p.20) prevê que:

Os objetivos da educação de jovens e adultos, vistos como um processo de longo prazo, [...] deverão desenvolver [...] a autonomia e o senso de responsabilidade das pessoas e das comunidades, fortalecendo a capacidade de lidar com as transformações que ocorrem na economia, na cultura e na sociedade como um todo; promovendo a coexistência, a tolerância e a participação criativa e crítica dos cidadãos em suas comunidades, permitindo assim que as pessoas controlem seus destinos e enfrentem os desafios que encontram à frente.

Transpondo, porém, tais considerações para o universo prático da Educação de Jovens e Adultos em nossa sociedade logram-se caracterizações de um quadro de incisiva deficiência que vem acompanhado de um importante descompasso em termos do produto qualitativo do ato de educar. Contexto este que se estende desde sua estruturação enquanto proposta educacional pública.

Compreensões diversas do conceito da cidadania são encontradas em contextos e situações diferentes. Seu sentido mais pleno aponta para a possibilidade efetiva na produção e usufruto de valores e bens de um determinado contexto, na configuração que se dá a esse contexto, e para o reconhecimento do direito de falar e ser ouvido pelos outros.

Desse modo, a vida humana ganha sua riqueza se é construída e experimentada tomando como referência o princípio da dignidade. Segundo esse princípio, toda pessoa e qualquer pessoa é digna merecedora do respeito dos seus semelhantes, e tem direito a boas condições de vida e a oportunidade de realizar seus projetos. Baseado nos conhecimentos adquiridos durante minha vivência acadêmica instrumentalizo em Delors (2000) que enfatiza a educação, como condição necessária para as próximas gerações, quatro saberes fundamentais: aprender a aprender, aprender a fazer e aprender a 
conviver. E para isso, a escola deve ter como tarefa a formação da cidadania e se esta ganha seu sentido pleno num contexto democrático, e fundamental verificar que situação existe hoje no Brasil. As Leis que regem as ações do povo brasileiro apontam efetivamente na direção da cidadania. A atual Lei de Diretrizes e Bases da Educação Nacional (Lei no. 9.394, de 20/12/96), em seu título II, artigo $2^{\circ}$, afirma que "a educação, dever da família e do estado, inspirada nos princípios de liberdade e nos ideais de solidariedade humana, tem por finalidade o pleno desenvolvimento do educando, seu preparo para o exercício da cidadania e sua qualificação do mercado".

Segundo Pedro Demo, do ponto de vista estratégico, a educação é o fator mais decisivo, mais nunca de modo setorial isolado; assim, essa idéia implica que os fatores do desenvolvimento se hierarquizam e se consertam, ao mesmo tempo.

Verifica-se, portanto, uma preocupação com a dimensão moral da educação e uma dimensão de contemplá-la nas propostas que se apresentam na sociedade. Como instituição especificamente destinada à educação, a escola deve empenhar-se na formação moral de seus alunos, embora não seja a única instituição social que participa dessa formação. Desse modo, para construir um mundo melhor não implica apenas descobrir de quem é a culpa pelos erros atuais, ou apontar erros, ou querer respostas imediatas, pois nenhuma mudança ocorrerá agora. Transformar o foi sedimentado ao longo de anos supõe vontade, coragem e persistência.

Cientes da imensidão dessa responsabilidade e desafios têm que assumir nosso comprometimento ético para com nossos alunos, para com a sociedade em que vivemos, para com cada um de nós como gente, na certeza de que, apesar do inesperado das diversas circunstancias, sempre vale a pena educar.

A cidadania assim construída passa a ser um compromisso público integrado à personalidade de cada um, onde a efetivação do ser ético acontecerá em todas as dimensões. Podemos dizer que se a educação assumir este compromisso desafiador estará acima de tudo, transformando-se 
no verdadeiro elo entre o que temos e o que sonhamos: um mundo melhor, mais feliz, mais justo, mais humano, acima de tudo, mais ético.

Sendo assim, a EJA se constitui como um direito à vida cidadã, isto é, como uma possibilidade de inclusão para quem não teve na idade dita adequada ou padrão, a oportunidade de concluir seus estudos ou sequer começá-los. Impossibilitados, por inúmeros motivos, atropelaram o percurso de homens e mulheres, jovens e adultos ao longo de seus caminhos, causando descaminhos prejudiciais à vida social, bem como suas relações no/com o mundo em diferentes episódios.

\section{CONSIDERÇÔES FINAIS}

O exposto trabalho veio mostrar a importância da alfabetização com alunos da EJA, para que esses indivíduos possam ter oportunidades em todo meio social igual aos demais alunos que tiveram no tempo correto, trouxe também algumas discussões sobre a formação e informação que os professores dessa modalidade de ensino precisa saber para exercer sua função alfabetizadora, sendo que a parceria com a equipe pedagógica é de fundamental relevância e quando esse supervisor exercer suas atribuições de forma correta auxiliando seus professores e alunos em suas dificuldades 0 processo ensino aprendizagem torna-se mais fácil.

Portanto o presente trabalho buscou através da pesquisa e conversação com alguns autores conhecedores do trabalho com alunos da EJA, que a construção do conhecimento, parte de um conhecimento já adquirido, e que o diagnóstico da turma facilita e aproxima o alfabetizando do querer aprender. 


\section{REFERÊNCIAS}

ALMEIDA, Laurinda e PLACCO, Vera. O coordenador pedagógico e o espaço da mudança. Ed. Layola. São Paulo. 2002.

CONFERÊNCIA INTERNACIONAL SOBRE A EDUCAÇÃO DE ADULTOS, V: 1997,Hamburgo, Alemanha. Declaração de Hamburgo: agenda para o futuro. Brasília: SESI;UNESCO, 1999. 67p. Disponível em:

<http://unesdoc.unesco.org/images/0012/001297/129773porb.pdf >. Acesso em 13 Nov.2007.

DURANTE, Marta. Alfabetização de adultos: Leituras e produção de textos. Grupo A. Porto Alegre. 1998.

DELORES,J. ( Org. ). Educação: um tesouro a descobrir. São Paulo: Cortez; Brasília: MEC/UNESCO,2000.

DEMO PEDRO, Educação e desenvolvimento: Nito e realidade de uma relação possível e fantasiosa São Paulo: Papirus, 1999.

FREIRE, PAULO Pedagogia do oprimido $17^{\underline{a}}$ ed. Rio de Janeiro, Paz e terra, 1987.

---------, Pedagogia da Autonomia: Saberes necessários a prática Educativa. 15 ed. São Paulo: paz e terra, 1996.

FERREIRA, Aurélio. Mini Aurélio: 0 minidicionário da língua portuguesa. Ed. Nova Fronteira. Rio de Janeiro. 2002.

FERREIRA, Daisy A EDUCAÇÃo DE JOVENS E ADULTOS, 2008. Disponível em: http://www.diaadiaeducacao.pr.gov.br/portals/pde/arquivos/1711-6.pdf. 
FREIRE, Paulo. Pedagogia da autonomia: Saberes necessários à prática educativa. Ed. Paz e terra. São Paulo. 2002.

GONÇALVES, Romanda. Didática Geral. Ed. (enriquecida e novos assuntos, atualizada e refundida. Rio de Janeiro. 1982.

LDB - Lei de Diretrizes e Bases da Educação: Dos níveis e das modalidades de educação e ensino, 1996, Disponível em: http://www.cpt.com.br/ldb/dosniveis-e-das-modalidades-de-educacao-e-ensino.

LUCKESI, CIPRIANO, Carlos Filosofia da Educação. São Paulo: Cortez, 1994.

LUCKESI, CIPRIANO, Carlos Filosofia da Educação. São Paulo: Cortez, 1994.

LOPES, Selva E SOUZA, Luzia EJA: UMA EDUCAÇÃo POSSíVEL OU MERA UTOPIA?, S.D. Disponível em: http://www.cereja.org.br/pdf/revista_v/revista_selvaplopes.pdf.

ORTIZ, Mara Fernanda Alves. Educação de Jovens e Adultos: um estudo do nível operatório dos alunos. 2002. 156 f. Dissertação (Mestrado em Educação)

- Faculdade de Educação, Universidade Estadual de Campinas, Campinas, 2002. Disponível em: <

http://libdigi.unicamp.br/document/?code=vtls000248391>Acesso em: 23 Out. 2006.

RIBEIRO, Vera Maria Masagão. (Coord.) Educação para Jovens e Adultos: Ensino Fundamental: Proposta curricular-1 ${ }^{\circ}$ segmento. São Paulo: Ação Educativa; Brasília: MEC,2001. 239 p. Disponível em:<http://portal.mec.gov.br/secad/arquivos/pdf

SCHWARTZ REVISTA: nova Escola, a revista do ensino do primeiro grau. Ano X, №. 86.Agosto, 1995.

SAVIANI, DERNEVAL, Educação: do senso comum a consciência filosófico - São Paulo: Cortez - 1986.

Suzana. Alfabetização de Jovens e Adultos. Ed.Vozes. Petrópolis, RJ. 2010. 
SILVA, João. Ensino de história em EJA: Identidade e Imagens. Ed. Moderna. São Paulo. 2012.

SOEK, Ana, HARACEMIV, Sonia e STOLTZ, Tânia. Mediação Pedagógica na alfabetização de Jovens e Adultos. Ed. Positivo. Curitiba. 2009. 